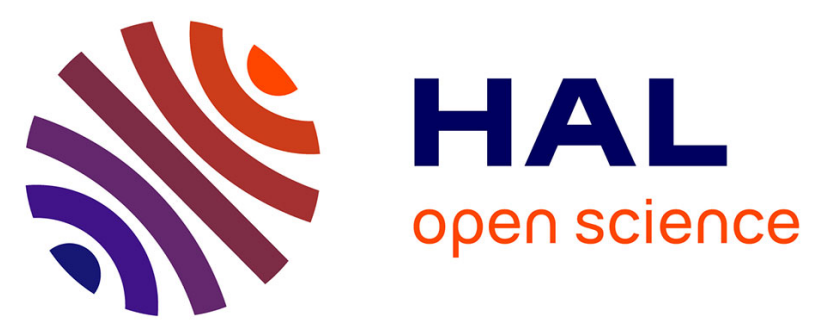

\title{
A decade-long surveillance of nasopharyngeal colonisation with among children attending day-care centres in south-eastern France: 1999-2008
}

B. Dunais, P. Bruno-Bazureault, H. Carsenti-Dellamonica, P. Touboul, C. Pradier

\section{To cite this version:}

B. Dunais, P. Bruno-Bazureault, H. Carsenti-Dellamonica, P. Touboul, C. Pradier. A decade-long surveillance of nasopharyngeal colonisation with among children attending day-care centres in southeastern France: 1999-2008. European Journal of Clinical Microbiology and Infectious Diseases, 2011, 30 (7), pp.837-843. 10.1007/s10096-011-1154-9 . hal-00701253

\section{HAL Id: hal-00701253 \\ https://hal.science/hal-00701253}

Submitted on 25 May 2012

HAL is a multi-disciplinary open access archive for the deposit and dissemination of scientific research documents, whether they are published or not. The documents may come from teaching and research institutions in France or abroad, or from public or private research centers.
L'archive ouverte pluridisciplinaire HAL, est destinée au dépôt et à la diffusion de documents scientifiques de niveau recherche, publiés ou non, émanant des établissements d'enseignement et de recherche français ou étrangers, des laboratoires publics ou privés. 
A decade-long surveillance of nasopharyngeal colonisation with Streptococcus pneumoniae among children attending day-care centres in South-Eastern France: $1999-2008$.

Brigitte Dunais, MD, Pascale Bruno, MD, Hélène Carsenti, PharmD, Pia Touboul, MD, Christian Pradier, PhD.

Public Health Department, Hôpital de l'Archet, CHU de Nice, BP 3079, 06202 Nice cedex 3, France

Corresponding author:

Brigitte Dunais

Département de Santé Publique

Hôpital l'Archet 1

BP 79

06202 Nice cedex 3

France

Telephone +33492035635

Fax +33492035627

Email: dunais@chu-nice.fr 


\section{ABSTRACT}

Purpose: Antimicrobial resistance and serotype distribution of Streptococcus pneumoniae (SP) among children attending day-care centres in Southeastern France were monitored from 1999 to 2008, before and after interventions promoting prudent antibiotic use initiated in 2000 and availability of pneumoccal conjugate vaccine in 2003. Methods: Antibiotic susceptibility and serotypes of SP isolates were determined on nasopharyngeal samples of children aged 3-40 months attending daycare centres, from January to March 1999, 2002, 2004, 2006, 2008. Results: SP carriage fell from $54 \%$ to $45 \%$, and SP with diminished susceptibility to penicillin (PDSP) from $34 \%$ to $19 \%$. Antibiotic prescriptions dropped from $63 \%$ to $38 \%$ of children, but $3^{\text {rd }}$ generation cephalosporins were increasingly prescribed. Overall antibiotic susceptibility increased. Over $90 \%$ of the children had received at least one vaccine dose in 2008. Vaccine serotypes 6B, 9V, 19F, 23F (76\%) in 1999 were replaced by non-vaccine types $(95 \%)$ in 2008 , among which $15(20 \%), 19 \mathrm{~A}(15 \%)$, 23A/B (10\%) and $6 \mathrm{~A}(9 \%)$. Serotypes $6 \mathrm{~A}, 19 \mathrm{~A}$ and 15 accounted for over $50 \%$ of PDSP strains in 2008 vs. $6 \%$ in 1999. Conclusion: Children now mostly harbour non-vaccine types; however PDSP isolates are mainly recruited among these. Vaccine-related benefits may be threatened by combined vaccine- and antibioticdriven selective pressure. 


\section{Introduction}

Since the seven valent pneumococcal conjugate vaccine became available, several studies in France and abroad have reported shifts in pneumococcal distribution as observed in blood or cerebrospinal fluid samples in the context of invasive disease, or in nasopharyngeal samples in that of acute otitis media [1,2]. Healthy day-care centre (DCC) attendees are known to be the major reservoirs and disseminators of pneumococci so that carriage surveillance in this particular setting provides a reasonably accurate estimate of the distribution of pneumococcal strains circulating within the community [3,4]. Frequent nasopharyngeal carriage of penicillin-nonsusceptible Streptococcus pneumoniae (PDSP) and exposure to numerous antibiotic treatment courses were observed in the late 1990s among children attending DCCs in the Alpes Maritimes (AM), in South-eastern France [5]. In an effort to curb one of the highest rates of pneumococcal resistance and antibiotic use in Europe [6], an intervention promoting prudent antibiotic use in the context of paediatric respiratory tract infections was implemented in AM in 2000, based on academic detailing visits to all local general practitioners and paediatricians[7]. It was followed by a nationwide media campaign initiated in 2002 [8], while the 7-valent pneumococcal conjugate vaccine became available and its cost endorsed by the national health insurance early 2003. Pneumococcal carriage and antibiotic-resistance trends in DCCs were monitored in AM on an ongoing basis, from 1999 to 2008, allowing assessment of the combined impact of both these events on carriage in this particular setting [9]. We report trends in carriage, serotype distribution and antibiotic susceptibility of SP over the ten-year period from 1999 to 2008.

\section{Methods}

Cross-sectional surveys were conducted on a random sample of children attending group day-care from January to March 1999, 2002, 2004, 2006 and 2008. Updated lists of all the DCCs were obtained from the local public health authorities for each survey. Care-center managers and attending physicians were informed of the survey and their eventual participation was requested in the event that they were randomly selected. For each survey, a two-stage cluster sample was obtained via a random sample of DCCs among which a random sample of 22 children was drawn, allowing 
for potential refusal by parents or absentees on the day of the survey. Only those children spending at least three days a week in the centre were included in the sampling frame. Refusal of a DCC centre to participate led to an offer of participation to the next centre on the list, in order to include 25 centres for each survey. In case parents agreed, they were asked to sign an informed consent document and to provide the child's health booklet, which is usually completed by the child's attending physician at each medical visit, and to complete a questionnaire concerning the child's recent medical history and antibiotic treatments over the previous three months. Only those treatments where parents could provide the name of the antibiotic were recorded. On the day of the survey the investigating physician recorded the immunization status for PCV7 from the children's health booklets and in some instances, when the booklet was not available, immunization status was provided by the DCC records. Since very few children received the vaccine before 2004, analysis of pneumococcal carriage and serotype distribution according to immunization status was conducted only for the 2004, 2006 and 2008 surveys.

Nasopharyngeal aspirates were obtained using a Vygon® 522.06 canula adapted on a $1 \mathrm{~mL}$ syringe. The canula was then transferred in a transport medium (Portagerm®, Biomérieux, Lyon) to the Laboratoire d'Antibiologie of Nice University Hospital.

The study protocol was approved by the Nice University Hospital Ethics committee.

\section{Microbiology}

Samples were submitted to direct microscopic examination and cultured on blood agar. Pneumococcal isolates were identified by Gram stain and susceptibility to optochin. Susceptibility of pneumococcal isolates to antibiotics was determined by disc diffusion to oxacillin $(1 \mu \mathrm{g}$ and $5 \mu \mathrm{g})$, erythromycin, clindamycine, chloramphenicol, and tetracycline. Susceptibility to trimethoprime/sulfamethoxazole combination was tested on separate lysed blood agar plates. Penicillin, amoxicillin and ceftriaxone minimal inhibitory concentrations (MICs) were determined for strains with an $1 \mu \mathrm{g}$ oxacillin diameter below $19 \mathrm{~mm}$ and/or oxacillin $5 \mu \mathrm{g}$ below $26 \mathrm{~mm}$ by $\mathrm{E}$ test ${ }^{\circledR}$ (BMD, France) and strains were classified as penicillin-intermediate $(\mathrm{MIC}>0.064 \mathrm{~g} / \mathrm{ml})$ or penicillin-resistant $(\mathrm{MIC}>1 \mu \mathrm{g} / \mathrm{ml})$ according to the recommendations put forward by the Antibiogram Committee of the French Microbiological Society (Comité de l'Antibiogramme de la Société Française de 
Microbiologie: http://www.sfm.asso.fr). Breakpoints for amoxicillin and ceftriaxone were $>0.5 \mu \mathrm{g} / \mathrm{ml}$ and $>2 \mu \mathrm{g} / \mathrm{ml}$, respectively. Serotypes were analysed using the Quellung reaction with antisera provided by the Statens Serum Institute (Copenhagen, Denmark). These antisera concerned the following serotypes: 6A, 6B, 9V, 14, 19A , 19F, 23F, and 24. In 2004, strains not reacting with any of those antisera were sent to the National Pneumococcal Reference Center in Paris for identification. From 2006, all serotype determinations, including formerly unidentified serotypes of stored isolates from the previous surveys, were conducted in the Laboratoire d'Antibiologie of Nice University hospital with pneumococcal latex pool antisera and factor antisera from the Serum Statens Institute to identify specific serotypes included in the PCV7 formulation.

\section{Regional epidemiology}

Antibiotic prescription rates were confronted with regional sentinel surveillance data provided by the regional influenza surveillance sentinel physicians (Groupe Régionaux d'Observation de la Grippe). This surveillance is conducted every year from October $1^{\text {st }}$ (week 40) to April $15^{\text {th }}$ (Week 15), as participating physicians report every week the number of patients with influenza-like respiratory tract infection among children aged 0 to 4 years. The available aggregated regional data for the Provence Alpes Côte d'Azur region include the Alpes Maritimes area.

\section{Sample size}

In order to estimate the proportion of SP carriers within 5\% and with $95 \%$ confidence, with a hypothesis $25 \%$ carriers of non-susceptible isolates, the required sample size for each survey was calculated to be 288 .

\section{Statistical analysis}

Data were analyzed using Epi-Info $6 \mathrm{c}$ and $\mathrm{SPSS}^{\odot}$ software. Univariate analysis was performed using the chi-square test with a $5 \%$ degree of significance. Means were compared using ANOVA or non-parametric Kruskall Wallis' test for unequal variances. 


\section{Results}

Population characteristics (Table 1)

The AM in South-Eastern France has a population of approximately one million, and a birth rate of 11 per 1,000 inhabitants. In France, DCCs cater for children aged 3 months to 3 years of age. There were 58 DCCs in 1999 with a total capacity of 2,800 children. This increased gradually over the years to reach 97 DCCs with an overall capacity of approximately 5,000 attendees in 2008. Over the five surveys, nasopharyngeal samples were obtained from a total of 1,604 children distributed among the 25 DCCs, aged 3 to 39 months. The number of participating children and their characteristics for each survey are described in Table 1. No major variation in distribution by age and gender was observed over the study period.

\section{Antibiotic prescriptions}

The proportion of children who received an antibiotic prescription within the three months prior to enrolment, as reported by parents, decreased by $50 \%$ between 1999 and 2006, but this trend was not sustained in 2008 (37.9\% in 2008 versus 30.9\% in 2006; $p=0.06$ ). These results were confirmed when considering data entered in children's health booklets. The mean number of treated episodes per child also decreased until 2006, but again the trend did not persist beyond that year (Table 2). Patterns of antibiotic prescription changed over the study period, with $3^{\text {rd }}$ generation cephalosporins accounting for $48 \%$ of prescriptions in 2008 against $23 \%$ in 1999 $\left(p<10^{-3}\right)$, and amoxicillin \pm clavulanate for $39 \%$ against $50 \%$, respectively $(p=0.035)$.

Antibiotic use was associated with a lower pneumococcal carriage rate $(36.2 \%$ among treated children vs $50.7 \%$ among untreated children; $\mathrm{p}=0.008$ ) but not with PDSP carriage (18.5\% versus $18.8 \%$, respectively).

\section{Pneumococcal immunization}

Pneumococcal immunization rates with the 7-valent conjugate vaccine, as recorded from children's health booklets or by the care centre staff, increased steadily from 2004, with at least 9 out of ten children having received at least one dose in 2008. That year, among 224 children above the age of 18 months, $92.4 \%$ had received three doses. 


\section{Pneumococcal carriage and serotype distribution}

From 1999 to 2008, overall pneumococcal carriage decreased from $54 \%$ to $45 \%$, and carriage of penicillin non-susceptible strains dropped from $33.9 \%$ to $18.7 \%$, respectively.(Table 1)

Serotype distribution for each survey is shown in Figure 1. Vaccine serotypes accounted for $4.4 \%$ of all identified serotypes in 2008 , down from $77.0 \%$ in 1999 , $\left(p<10^{-3}\right)$, and were mainly replaced by serotypes $15,19 \mathrm{~A}, 23 \mathrm{~A} / \mathrm{B}$ and $6 \mathrm{~A}$ which all increased at least five-fold and accounted for $55 \%$ of isolates in 2008. Serotype 15 was the most abundant in 2008, accounting for $20 \%$ of isolates and recovered in samples from $50 \%$ of DCCs that year (Figure 2).

\section{Antibiotic susceptibility}

Overall, susceptibility to all tested antibiotics increased significantly over the study period, up to the 2006 survey ( $p<10^{-3}$ for each tested antibiotic) and then stabilized (Figure 3). In particular, the proportion of isolates non-susceptible to erythromycin dropped from $70.2 \%$ in 1999 to $42.9 \%$ in 2006 and $47.2 \%$ in 2008. But in 2008, fewer strains were susceptible to chloramphenicol and co-trimoxazole compared with 2006. The proportion of isolates non-susceptible to 3 or more antibiotics, which had dropped from $55.9 \%$ in 1999 to $29.2 \%$ in 2006 , rose to $47.4 \%$ in 2008 , a significant increase compared to the previous survey $\left(\mathrm{p}<10^{-3}\right)$, and these MDR strains were mainly serotypes $19 \mathrm{~A}, 15$ and $6 \mathrm{~A}$, representing $32.9 \%, 16.4 \%$ and $13.7 \%$ of MDR isolates, respectively, in 2008. In particular, 15 out of 32 serotype 15 isolates were non-susceptible to erythromycin, and 11, 3 , and 4 isolates of this serotype were intermediately susceptible to penicillin, amoxicillin, and ceftriaxone, respectively. Among vaccine-types, penicillin susceptibility increased from $38.7 \%$ to $74.3 \%$ of strains from 1999 to 2006, while in 2008, among the 7 remaining vaccine-type isolates, 3 were not fully susceptible. In 2008 the majority of PSDP isolates were 19A (35.9\%), 6A (12.5\%), 23A/B (6.3\%), and 15 (15.6\%).

Penicillin MICs of most PDSP isolates remained at the intermediate level and no significant change was observed regarding MIC distribution. None were resistant to either amoxicillin or ceftriaxone over the study period, although $41 \%$ and $50 \%$ were not fully susceptible to these respective compounds in 2008 (Figure 4), and that year 
serotype $19 \mathrm{~A}$ accounted for $57 \%$ of amoxicillin non-susceptible and $55 \%$ of ceftriaxone non-susceptible isolates (Figure 5).

\section{Regional epidemiology}

Data from the respiratory tract infection community-based sentinel surveillance group for the PACA region show a peak incidence rate in the 2001-2002 Winter season for the 0 to 4 year-old age group (Figure 5) although no increase in antibiotic prescriptions was observed among day care attendees that year. A higher mean rate of respiratory tract infection was observed in 2007-2008 compared to 2005-2006 (2.18 \pm 0.87 vs. $1.86 \pm 0.78$, respectively). However, the difference was not significant.

\section{Discussion}

Our five consecutive surveys describe a ten-year trend in pneumococcal carriage among healthy children who attended a day-care centre at least 3 days a week in South-eastern France, covering a period which saw the introduction and wide use of pneumococcal conjugate vaccine, and the implementation of campaigns to reduce antibiotic prescriptions. Such surveys provide an insight into the epidemiology of Streptococcus pneumoniae within the community, the day-care setting being notorious for the high carriage rates among its young attendees [3,4]. As major contributors to SP prevalence in the community, DCC attendees may be considered as sentinels providing an advanced warning system for trends in pneumococcal infection, through regular carriage monitoring in this setting. Huang et al. developed a model exploring both individual- and community-level effects of DCC attendance and suggested that the mere presence of DCCs within a community led to a 6 fold increase in the odds of carriage for non-attendees [4].

Although the decline in pneumococcal carriage was moderate, our results show a significant overall drop in carriage rates of PDSP over the 10-year period concerned, along with fewer antibiotic prescriptions. Considering the high prevalence rates of PDSP initially recorded among this population in the late 1990s, these results are reassuring and confirm those observed both in France and abroad [10,11]. In central Greece, wide coverage with PCV7 vaccination was followed by a significant reduction 
of carriage of highly-penicillin resistant pneumococci among DCC attendees[11]. In France, widespread pneumococcal immunization combined with a local, followed by a nationwide campaign to curb antibiotic prescriptions, appears to have demonstrated its effects [12]. In a study focusing on children with acute otitis media in France between 2001 and 2006, Cohen et al. observed decreasing carriage rates from $71 \%$ to $62 \%$, and antibiotic prescriptions from $51 \%$ to $38 \%$, with a concomitant rise in penicillin susceptibility, from $23 \%$ to $35 \%$ of isolates, as immunisation rates reached $91 \%$ [2]. In our study, antibiotic use dropped by over a third between 1999 and 2008. The respective impact of each of these two measures, i.e. pneumococcal immunization and public health campaigns, is difficult to assess in the absence of resistance data concerning other current pathogens over the study period. However, national French observatories for resistance trends among various organisms report decreasing proportions of methicillin-resistant Staphylococcus aureus isolates between 2001 to 2007 , according to several surveillance schemes, from $33 \%$ to $26 \%$, in favour of an impact of interventions to reduce antibiotic prescriptions [13]

Likewise, serotype distribution has followed trends observed elsewhere. In Portugal, Sa-Leao et al. observed a decrease of vaccine types (VT) from $53 \%$ in 2001 to $11 \%$ in 2006 among children attending DCCs, with $57 \%$ vaccinees that year [3]. Huang et al. observed in 2007 that prevalence of VT was reduced to $3 \%$ of isolates among SP carriers in a study concerning children aged 3 to 84 months attending primary care centres in Massachusetts[14]. In our study, VT accounted for only $4 \%$ of carriage strains in 2008 with over $90 \%$ of children immunized with PCV7. However, although as elsewhere we found high prevalence rates of $19 \mathrm{~A}$ strains, among which $96 \%$ were non-susceptible to penicillin in 2008, the predominant strain that year was serotype 15 , of which $34 \%$ displayed non-susceptibility to penicillin. Due to the two-year delay between other carriage studies in France and Portugal and our own, it may be that serotype 15 is emerging as a major colonising serotype.

Our positive results should thus be considered with caution, as trends in both antibiotic prescription and carriage of non-susceptible pneumococci appear to have presently stabilized. Regarding antibiotic use, regional sentinel surveillance data do not suggest an increase in the incidence rate of respiratory tract infections in 2008 which would account for the lack of further progress in reducing prescriptions. Whether the present prescription rate among children attending DCCs should be considered as the best we can achieve in France remains to be determined. It may 
be that sustained efforts are necessary to restrain antibiotic use, and the public health campaign that was implemented in France during 2003-2004 has not been sufficiently reinforced, nor specifically targeted towards DCC directors, whose exclusion policies have been shown, in a study conducted in Minnesota, to exert a major influence on antimicrobial prescription [15].

Pneumococcal carriage rates remain high, and, as observed by others, the increasing prevalence of penicillin non-susceptible serotypes 19A and 6A (included in the newly available PCV13) and that of other non-vaccine serotypes exhibiting antibiotic-resistance, namely serotype 15 (not included in PCV13), are a cause for concern[16]. Vaccine escape by genetic recombination at the capsular locus has been documented, with concomitant change of serotype and penicillin susceptibility.[17]

Surveillance of invasive pneumococcal disease reflects similar changes. In France, coverage by PCV7 of invasive pneumococcal isolates in children below 2 years of age dropped below $10 \%$ in 2008 , while the newly licensed 13-valent conjugate vaccine (PCV-13) covered $68 \%$ of those strains[18]. In a multicentre retrospective cohort study conducted in Northern France, the incidence rate of invasive pneumococcal disease observed among children below 2 years of age between 2005 and 2008 increased 6.5-fold, from $1.8 / 100,000$ to $11.9 / 100,000$, and was caused by non-vaccine serotypes[19].

Regarding antimicrobial treatment, although fewer antimicrobials have been prescribed, those most frequently used may yet interfere with attempts to curb resistance. Indeed, French guidelines recommend treating acute otitis media in children below 2 years of age with an amoxicillin-clavulanate combination or $3^{\text {rd }}$ generation cephalosporins; declining prescriptions for other respiratory tract infections (i.e. common colds) may influence distribution of prescribed antibiotics in favour of these compounds. Ease of administration (twice daily) makes $3^{\text {rd }}$ generation cephalosporins more attractive to parents and day-care personnel and have thus been increasingly favoured; however, they are known to select for resistant strains $[20,21]$. 


\section{Conclusion}

We have attempted to counter antibiotic-driven selective pressure with vaccine-driven selection, which has proved highly effective in reducing the incidence of invasive disease but also in modifying the nasopharyngeal pneumococcal niche by introducing new colonizing strains. At the same time, fewer antibiotic prescriptions have eased the burden of resistant organisms. However, previously infrequent replacement strains are now in turn developing antimicrobial resistance, demonstrating how easy it is to revert to the initial situation. A new, wider spectrum (13-valent) pneumococcal conjugate vaccine is now available in France, exerting yet more selective pressure. It is to be hoped that the benefits reaped in terms of reducing the burden of pneumococcal disease will not be outweighed by the potential virulence of replacement strains or the persistence of inappropriate antibiotic use.

\section{Acknowledgements}

The authors are grateful to the directors and staff of the day-care centres and to the parents and children who collaborated in the study.

These surveys were supported by Produits Roche, Wyeth Pharmaceuticals and the Nice University Hospital Program for Clinical Research, Nice, France

These results were presented at the $46^{\text {th }}$ InterScience Conference on Anti-microbial Agents and Chemotherapy in Washington, DC, 2008. 
Table 1: Characteristics of the study population

\begin{tabular}{|c|c|c|c|c|c|c|}
\hline & 1999 & 2002 & 2004 & 2006 & 2008 & $p$ \\
\hline $\begin{array}{l}\text { \# children } \\
\text { \# DCC }\end{array}$ & $\begin{array}{c}298 \\
25\end{array}$ & $\begin{array}{c}294 \\
25\end{array}$ & $\begin{array}{c}334 \\
25\end{array}$ & $\begin{array}{c}335 \\
25\end{array}$ & $\begin{array}{c}343 \\
25\end{array}$ & \\
\hline $\begin{array}{l}\text { Girls } \\
\text { Age group: }\end{array}$ & $52,0 \%$ & $41,2 \%$ & $53,0 \%$ & $49,3 \%$ & $51,6 \%$ & 0,056 \\
\hline $\begin{array}{l}<12 \text { months } \\
12-24 \text { months }\end{array}$ & $\begin{array}{l}15,1 \% \\
40,6 \%\end{array}$ & $\begin{array}{l}19,7 \% \\
38,4 \%\end{array}$ & $\begin{array}{l}14,7 \% \\
40,4 \%\end{array}$ & $\begin{array}{l}14,0 \% \\
35,5 \%\end{array}$ & $\begin{array}{l}10,5 \% \\
39,9 \%\end{array}$ & \\
\hline$>24$ months & $44,3 \%$ & $41,8 \%$ & $44,9 \%$ & $50,4 \%$ & $49,6 \%$ & ns \\
\hline SP carriers & 161 & 172 & 182 & 168 & 155 & \\
\hline$\%$ SP carriers & $54,0 \%$ & $58,5 \%$ & $54,5 \%$ & $49,9 \%$ & $45,2 \%$ & 0,01 \\
\hline PDSP carriers & 101 & 111 & 86 & 57 & 64 & \\
\hline \%PDSP carriers & $33,9 \%$ & $37,8 \%$ & $25,7 \%$ & $17,0 \%$ & $18,7 \%$ & $<0.001$ \\
\hline Antibiotic treatment ${ }^{*}$ & $62,7 \%$ & $52,8 \%$ & $48,0 \%$ & $30,9 \%$ & $37,9 \%$ & $<0.001$ \\
\hline $\begin{array}{l}\text { Mean number of } \\
\text { treated episodes/child } \\
\text { PCV7 Immunization }\end{array}$ & $0.84 \pm 0.87$ & $0.78 \pm 0.91$ & $0.65 \pm 0.82$ & $0.38 \pm 0.62$ & $0.46 \pm 0.67$ & $<10^{-3}$ \\
\hline immunized $^{* *}$ & $N / A^{* \star *}$ & $\mathrm{~N} / \mathrm{A}$ & $37,1 \%$ & $68,4 \%$ & $90,1 \%$ & $<0.001$ \\
\hline non-immunized & $\mathrm{N} / \mathrm{A}$ & $\mathrm{N} / \mathrm{A}$ & $44,6 \%$ & $17,9 \%$ & $6,4 \%$ & \\
\hline status unknown & & & $18,3 \%$ & $13,7 \%$ & $3,5 \%$ & \\
\hline
\end{tabular}

Figure 1: Serotype distribution over time

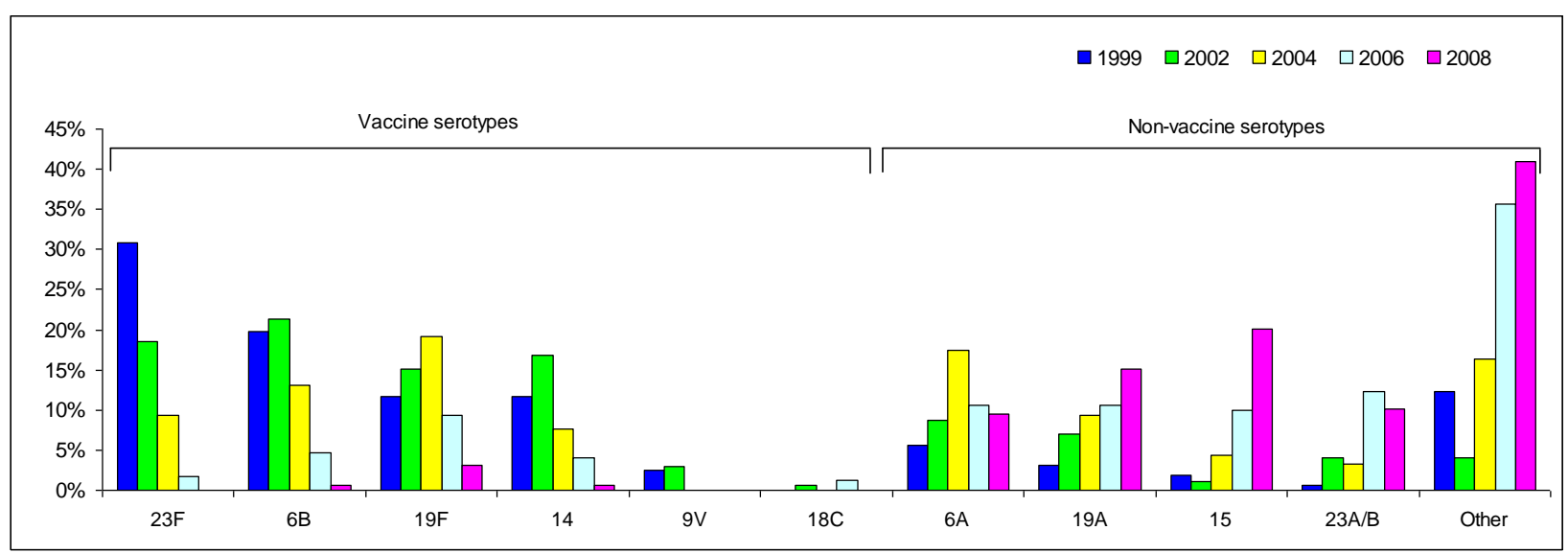


Figure 2: Distribution and penicillin-susceptibility of non vaccine types in 2008

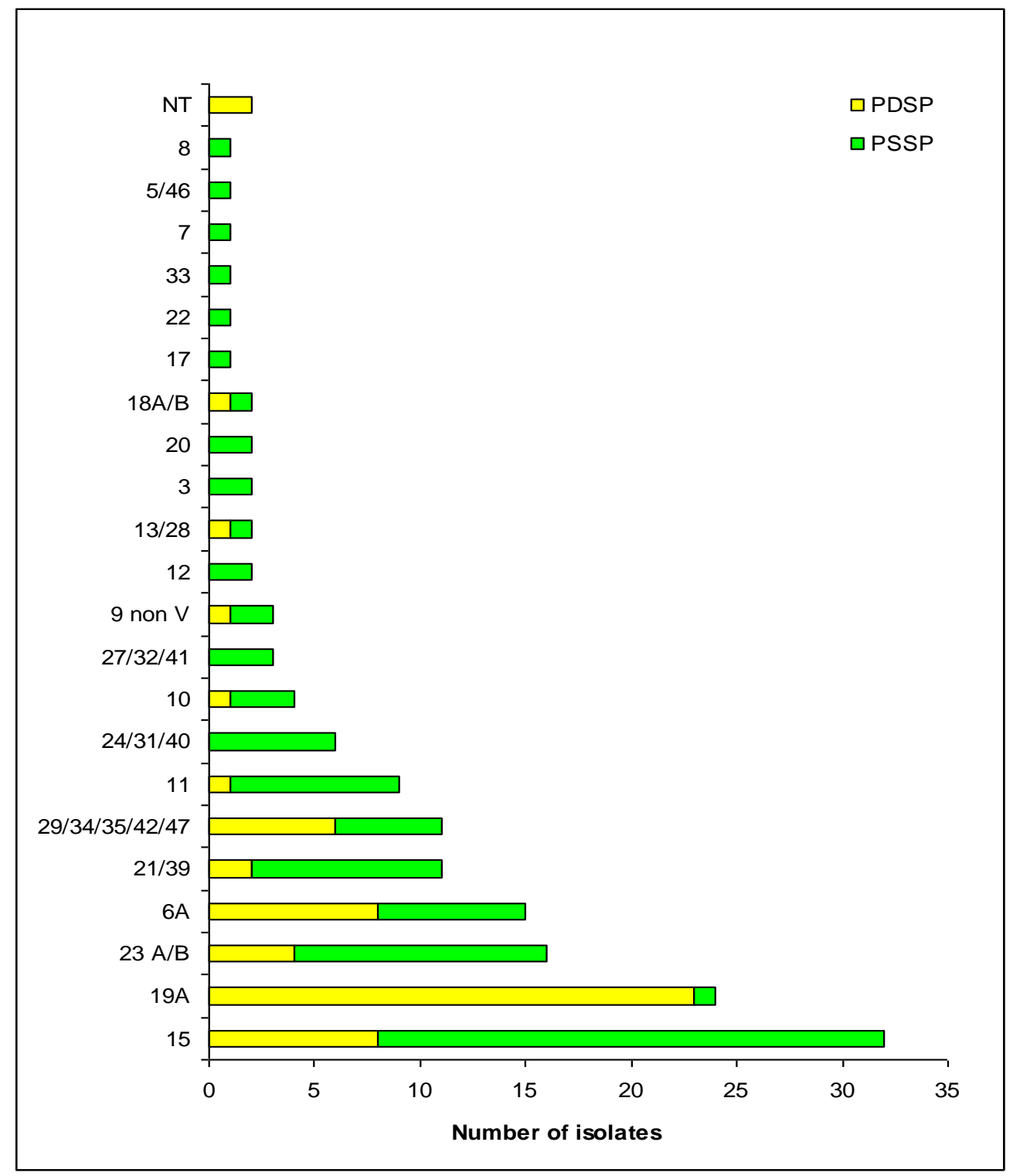


Figure 3: Trends in antibiotic susceptibility

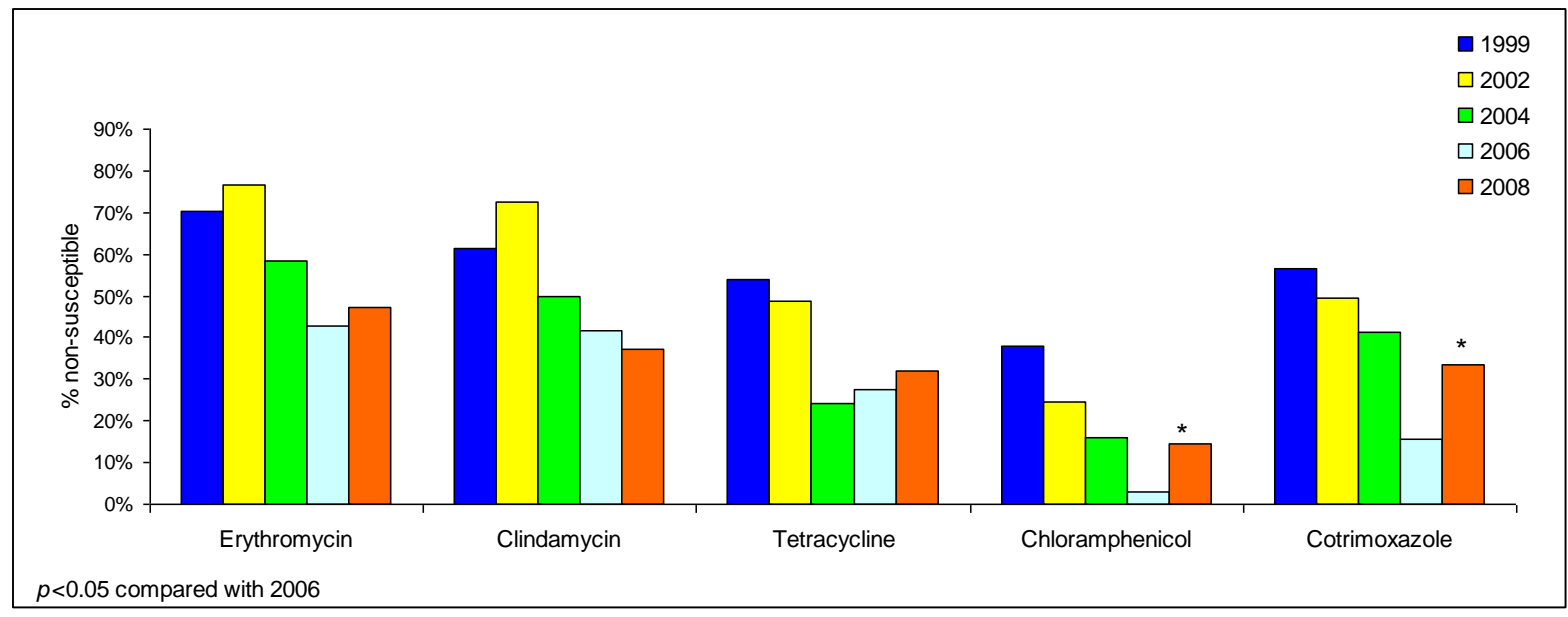

Figure 4: Susceptibility of PDSP to beta-lactams

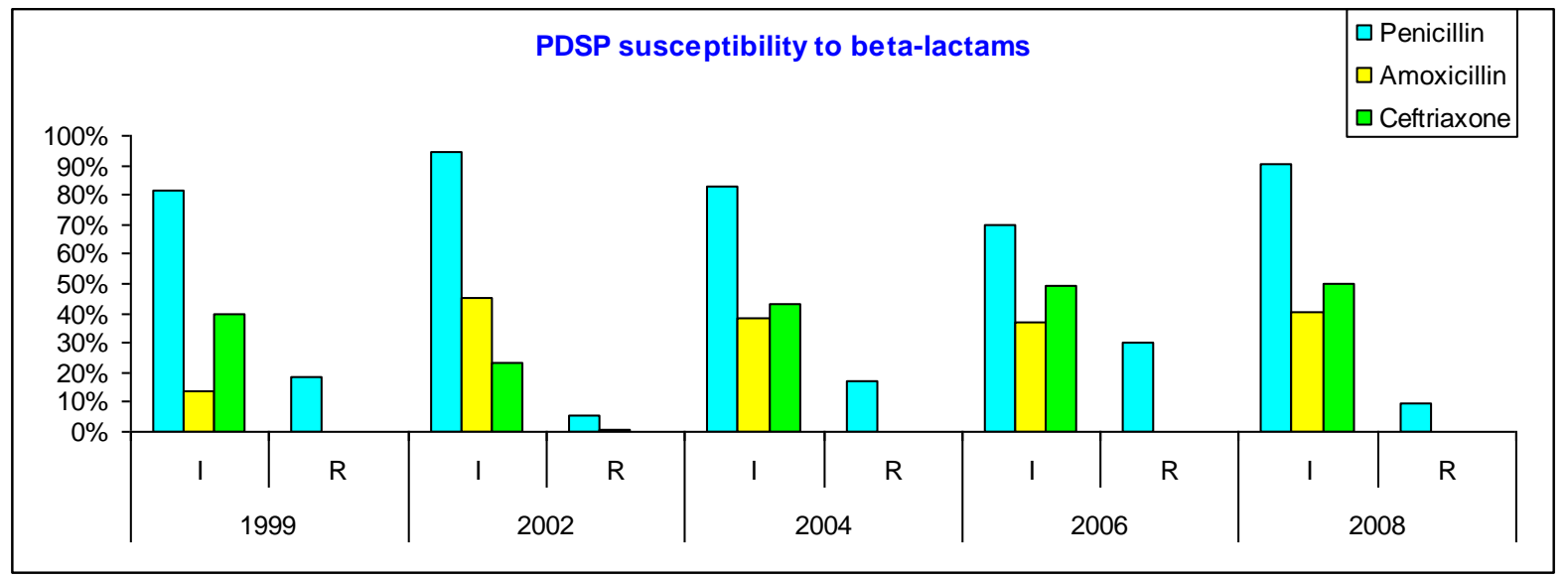

Figure 5: Weekly regional sentinel surveillance of respiratory tract infection

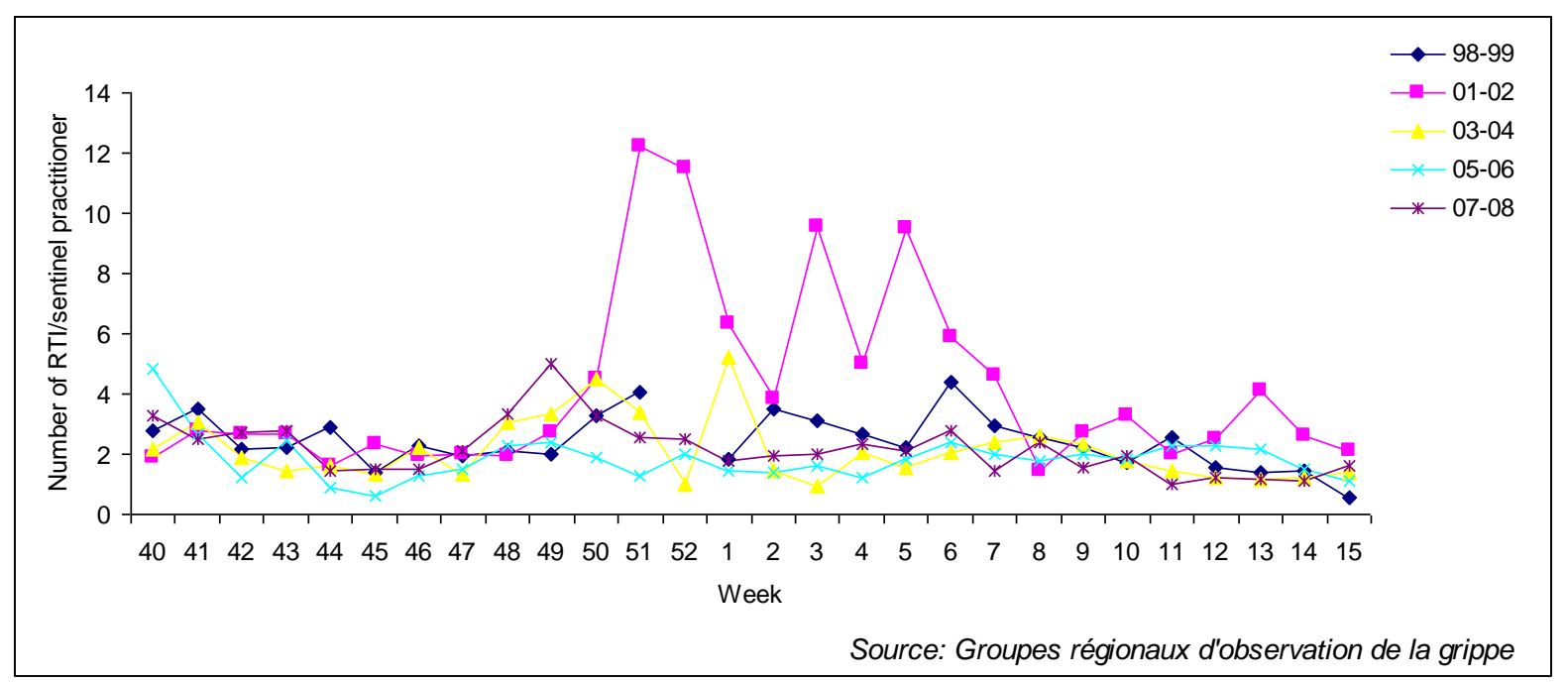




\section{References}

1 Doit C, Mariani-Kurkdjian P, Mahjoub-Messai F, Bidet P, Bonacorsi S, Carol A, Varon E, Bingen E. Epidemiology of pediatric community-acquired bloodstream infections in a children hospital in Paris, France, 2001 to 2008. Diagn Microbiol Infect Dis. 2010 Mar;66(3):332-5.

2 Cohen R, Levy C, Bonnet E, Grondin S, Desvignes V, Lecuyer A, Fritzell B, Varon E. Dynamic of pneumococcal nasopharyngeal carriage in children with acute otitis media following PCV7 introduction in France. Vaccine. 2009 May 30

3 Sá-Leão R, Nunes S, Brito-Avô A, Alves CR, Carriço JA, Saldanha J, Almeida JS, Santos-Sanches I, de Lencastre $\mathrm{H}$. High rates of transmission of and colonization by Streptococcus pneumoniae and Haemophilus influenzae within a day care center revealed in a longitudinal study. J Clin Microbiol. 2008 January; 46(1): 225-234

4 Huang SS, Finkelstein JA, Lipsitch M. Modeling community- and individual-level effects of child-care center attendance on pneumococcal carriage. Clin Infect Dis. 2005 May 1;40(9):1215-22.

5 Pradier C, Dunais B, Largillier R, Carsenti-Etesse H, Bernard E, Scheimberg A, Dellamonica P. Nasopharyngeal carriage of Streptococcus pneumoniae in children's day-care centers: 10-month follow-up study in Nice, France. Clin Microbiol Infect. 1997 Feb;3(6):705-708..

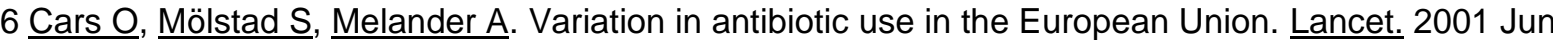
$9 ; 357(9271): 1851-3$.

7 Bruno-Bazureault P, Touboul P, Hofliger P, Mariné-Barjoan E, Pradier C, Patuano C, Dunais B, Dellamonica P; pour le Groupe d'étude et de prévention des infections de l'enfant (GEPIE).

[Peer visits to community-based general practitioners and pediatricians as part of the "Antibiotics only when necessary" campaign in the Alpes-Maritimes district. Methodology, feasibility, and interest] Presse Med. 2006 May;35(5 Pt 1):749-54.

8 Huttner B, Harbarth S "Antibiotics are not automatic anymore"--the French national campaign to cut antibiotic overuse. PLoS Med. 2009 Jun 2;6(6):e1000080. Epub 2009 Jun 2

9 Dunais B, Bruno P, Carsenti-Dellamonica H, Touboul P, Dellamonica P, Pradier C. Trends in nasopharyngeal carriage of Streptococcus pneumoniae among children attending daycare centers in southeastern France from 1999 to 2006. Pediatr Infect Dis J. 2008 Nov;27(11):1033-5.

10 Lepoutre A, Varon E, Georges S, Gutmann L, Lévy-Bruhl D. Impact of infant pneumococcal vaccination on invasive pneumococcal diseases in France, 2001-2006. Euro Surveill. 2008 Aug 28;13(35). pii: 18962.

11 Grivea IN, Panagiotou M, Tsantouli AG, Syrogiannopoulos GA. Impact of heptavalent pneumococcal conjugate vaccine on nasopharyngeal carriage of penicillin-resistant Streptococcus pneumoniae among day-care center attendees in central Greece. Pediatr Infect Dis J. 2008 Jun;27(6):519-25.

12 Sabuncu E, David J, Bernède-Bauduin C, Pépin S, Leroy M, Boëlle PY, Watier L, Guillemot D. Significant reduction of antibiotic use in the community after a nationwide campaign in France, 20022007. PLoS Med. 2009 Jun 2;6(6):e1000084.

13 Anonymous. Recent trends in antimicrobial resistance among Streptococcus pneumoniae and Staphylococcus aureus isolates: the French experience. Euro Surveill. 2008 Nov 13;13(46). pii: 19035. 
14 Huang SS, Hinrichsen VL, Stevenson AE, Rifas-Shiman SL, Kleinman K, Pelton SI, Lipsitch M, Hanage WP, Lee GM, Finkelstein JA. Continued impact of pneumococcal conjugate vaccine on carriage in young children. Pediatrics. $2009 \mathrm{Jul} ; 124(1): \mathrm{e} 1-11$

15 M'ikanatha NM, Gasink LB, Kunselman A, Warren K, Lautenbach E. Child care center exclusion policies and directors' opinions on the use of antibiotics. Infect Control Hosp Epidemiol. 2010 Apr;31(4):408-11

16 Dortet L, Ploy MC, Poyart C, Raymond J. Emergence of Streptococcus pneumoniae of serotype 19A in France: molecular capsular serotyping, antimicrobial susceptibilities, and epidemiology. Diagn Microbiol Infect Dis. 2009 Sep;65(1):49-57.

17 Brueggemann AB, Pai R, Crook DW, Beall B (2007) Vaccine escape recombinants emerge after pneumococcal vaccination in the United States. PLoS Pathog 3(11): e168. doi:10.1371/journal.ppat.0030168

18 Varon E. Janoir C. Gutmann L. Centre national de référence du pneumocoque. Rapport d'activité 2009. Available at : http://www.invs.sante.fr/surveillance/cnr/rapports pneumocoques2008.pdf

19 Alexandre C, Dubos F, Courouble C, Pruvost I, Varon E; the Hospital Network for Evaluating the Management of Common Childhood Diseases, Martinot A. Rebound in the incidence of pneumococcal meningitis in northern France: effect of serotype replacement. Acta Paediatr. 2010 Jul 7.

20 Dabernat H, Geslin P, Megraud F, Bégué P, Boulesteix J, Dubreuil C, de La Roque F, Trinh A, Scheimberg A. Effects of cefixime or co-amoxiclav treatment on nasopharyngeal carriage of Streptococcus pneumoniae and Haemophilus influenzae in children with acute otitis media. $J$ Antimicrob Chemother. 1998 Feb;41(2):253-8.

21 Dagan R, Barkai G, Leibovitz E, Dreifuss E, Greenberg D. Will reduction of antibiotic use reduce antibiotic resistance? The pneumococcus paradigm. Pediatr Infect Dis J. 2006 Oct;25(10):981-6. 